\title{
Supply Chain Inventory Problem with Price Increased and Demand Rate Depends on Retail Price
}

\author{
Chih-Te Yang and Liang-Yuh Ouyang
}

\begin{abstract}
This study investigates the supply chain inventory problems when the supply price increases and market demand rate depends on retail price. The purpose of this study will be to determine optimal special order quantity, retail price and production cycle by maximizing the increment of joint total profit. Furthermore, due to the vendor may or not provide all the special order quantity at the buyer's next replenishment date and hence the shortage will or not occur, two specific situations are discussed in this study. A simple algorithm to find the optimal solution is developed. Finally, several numerical examples will be presented to demonstrate the developed model and solution procedure to provide manager a useful decision consultation.
\end{abstract}

Index Terms-Inventory, deteriorating items, supply chain, price increase, price-dependent demand.

\section{INTRODUCTION}

Due to the recent increases in the prices of oil and raw materials, the prices of commodities have continued to increase worldwide. This has become a serious problem for enterprises. As the vendor announces an impending price increase due to take effect at a certain time in the future, it is important for the buyer to decide whether to purchase additional stock before the price increase, to take advantage of the present lower price. In many of the existing studies in this area, the authors have taken the announcement of a price increase problem into account and have proposed various analytical models to gain more insight into the inferences relating to inventory policy. Naddor [1] was one of the early researchers who proposed an infinite horizon economic order quantity (EOQ) model where the supplier announces a price increase. Lev and Soyster [2] developed a finite horizon inventory model and determined optimal ordering policies based on known information about an imminent price increase. Later, Goyal [3] analyzed Lev and Soyster's model and proposed an alternative method for determining the optimal policy. Taylor and Bradley [4] extended Naddor's model and obtained the optimal ordering strategies for situations where the price increase does not coincide with the end of an EOQ cycle. Lev and Weiss [5] subsequently developed a structure of optimal policies and procedures for computing the optimal policy. Goyal et al. [6] presented a

Manuscript received October 15, 2012; revised December 27, 2012. This research was partially supported by the National Science Council of the Republic of China under Grant NSC 100-2221-E-231-014.

Chih-Te Yang is with Department of Industrial Management, Chien Hsin University of Science and Technology, Taoyuan, Taiwan (e-mail: ctyang@uch.edu.tw).

Liang-Yuh Ouyang is with the Department of Management Sciences Tamkang University, Tamsui, New Taipei, Taiwan (e-mail: liangyuh@ mail.tku.edu.tw) review of a study on inventory policies under one-time only incentives. Tersine [7] proposed an economic production quantity (EPQ) model under an announced price increase. Ghosh [8] and Huang and Kulkarni [9] presented an infinite-horizon deterministic inventory model under an announced price increase. In contrast to single price change models, a small number of continuous price change models exist within inventory management literature. Recently, Sharma [10] developed inventory models on price increases or temporary price reductions when shortages are allowed and partial backordering.

The objective of supply chain management is to be efficient and cost-effective across the entire system; total system-wide costs, from inventories to transportation and distribution, need to be minimized. The process of finding the best system-wide strategy is known as global optimization [11]. To accomplish global optimization in the field of inventory management, the concept of joint economic lot size (JELS) is introduced to refine the well-known classical EOQ model. The JELS model for a single vendor-single buyer was first developed and introduced by Goyal [12]. Later, Banerjee [13] assumed that the vendor produced on a lot-for-lot basis in response to orders from a single buyer, and developed the JELS model. Goyal [14] extended Banerjee's model by relaxing the lot-for-lot assumption and assumed that the vendor's lot size was an integer multiple of the buyer's order size and examined a model for a single vendor-single buyer production inventory system. Furthermore, Lu [15] relaxed Goyal's assumption of a single vendor-single buyer and proposed a model in which the vendor could actually supply the purchaser in a number of equal smaller lot-sizes, even before completing the entire lot. Hahm and Yano [16] and Aderohunmu et al. [17] developed an integrated model to minimize the total relevant inventory cost for both the vendor and the buyer, which included transportation cost. Goyal [18] also allowed the first shipment to be made before the whole lot was produced, and proposed a policy in which the quantity delivered to the buyer was not identical every replenishment. Further literature in support of this includes [19]-[22].

Nevertheless, a weakness in above inventory models is that they neglect the deterioration of goods, a common phenomenon. It is well known that certain products, such as medicine, volatile liquids, fruits, and vegetables, will vaporize, spoil, or damage over time. For such products, losses due to deterioration cannot be ignored when determining the optimal ordering policy. Inventory problems relating to deteriorating items have been studied widely, for example Ghare and Schrader [23] were the first to establish an EOQ model for an exponentially-decaying item, for which there is constant demand. Later, Covert and Philip [24] 
extended this model and obtained an EOQ model for a variable deterioration rate, by assuming a two-parameter Weibull distribution. Philip [25] then developed an inventory model with a three-parameter Weibull distribution deterioration rate. Shah [26] extended Philip's model and considered the circumstances in which a shortage is allowed. Goyal and Giri [27] provided a detailed review of the deteriorating inventory literature since the early 1990s. Bakker et al. [28] have recently undertaken an up-to-date review of the advances made in the field of inventory control of perishable items (deteriorating inventory) since 2001. There is a vast amount of literature on deteriorating items, an outline of which can be found by reviewing [29]-[31] and others.

Consequently, the contribution of this paper, relative to previous studies, is that we explore a vendor-buyer supply chain inventory in the context of the following three issues: (1) when the buyer is informed by the vendor of a future price increase and decides whether to make a special order before the increase, and what their new retail price should be; and (2) the goods deteriorate at a constant rate. Furthermore, due to the vendor may or not provide all the special order quantity at the buyer's next replenishment date and hence the shortage will or not occur, two specific situations are discussed in this study.

\section{NOTATION AND ASSUMPTIONS}

The following notation and assumptions are used in this study:

\section{A. Notation}

$c$ vendor's unit production cost before the material price increase

$c_{r}$ vendor's unit production cost after the material price increase, $c_{r}>c$

$v$ vendor's unit supply price (i.e., buyer's unit purchasing cost) before the material price increase, $v>c$

$v_{r}$ vendor's unit supply price (i.e., buyer's unit purchasing cost) after the material price increase, $v_{r}>c_{r}$

$p$ buyer's unit retail price when the unit purchasing cost is $v, p>v$

$p_{r}$ buyer's unit retail price when the unit purchasing cost is $v_{r}, p_{r}>v_{r}$

$p_{s}$ buyer's unit retail price for the special order quantity, a decision variable

$D(p)$ market demand rate, which is a decreasing function of the unit retail price.

$S$ vendor's setup cost per setup

$A$ buyer's ordering cost per order

$P$ vendor's production rate

$h_{v}$ vendor's holding cost rate, as a fraction of the cost of the item carried in inventory per unit time, $0<h_{v}<1$

$h_{b}$ buyer's holding cost rate, as a fraction of the cost of the item carried in inventory per unit time, $0<h_{b}<1$ deterioration rate of the material, where $0 \leq \theta_{v}<1$ and is a constant

$\theta_{b}$ deterioration rate of the product, where $0 \leq \theta_{b}<1$ and is a constant

$\pi$ Buyer's unit shortage cost per unit time

$Q$ buyer's economic order quantity (vendor's economic production quantity) before the material price increase

$Q_{r}$ buyer's economic order quantity (vendor's economic production quantity) after the material price increase

$Q_{s}$ buyer's special order quantity (vendor's special production quantity) before the material price increase, a decision variable.

$T$ the length of buyer's replenishment cycle time before the material price increase

$T_{v}$ the length of vender's production cycle time before the material price increase

$T_{r}$ the length of buyer's replenishment cycle time after the material price increase

$T_{r_{v}}$ the length of vender's production cycle time after the material price increase

$T_{c}$ the length of time interval until the buyer places a special order..

$T_{s}$ depletion time for the quantity $Q_{s}$, a decision variable

$T_{s_{v}}$ production time for the quantity $Q_{s}$, a decision variable

$t_{s}$ the length of time in which the inventory is shortage, a decision variable

$J T P(p, T)$ joint total profit per unit time during the replenishment period $\mathrm{T}$.

$\operatorname{JTP}_{r}\left(p_{r}, T_{r}\right)$ joint total profit per unit time during the replenishment period $\mathrm{Tr}$.

$g_{1}\left(p_{s}, T_{s}\right)$ joint total profit increase between the special order and regular order during the special cycle time for case 1.

$g_{2}\left(p_{s}, t_{s}, T_{s}\right)$ joint total profit increase between the special order and regular order during the special cycle time for case 2.

\section{B. Assumptions}

1) There is single-vendor and single-buyer for a single product in this model.

2) The buyer orders a lot of size $Q$ per order. The vendor produces and delivers $Q$ units to the buyer in each production run.

3) For the vendor, shortages are not allowed whether the buyer makes a general or special order. For the buyer, shortages are allowed when making a special order.

4) When shortages occur, the unsatisfied demand is complete backlogged.

5) When the material price increases, the vendor will reflect it on the supply price (i.e., the buyer's purchase cost). In 
turn, the buyer will also reflect its purchase cost on the retail price.

6) The demand rate $D(p)$ is a non-negative continuous function of the retail price $p$, and satisfies $D^{\prime}(p)<0$ and $D^{\prime \prime}(p) \leq 0$.

7) In general, the special order quantity at the present price, $Q_{s}$, is always greater than or equal to the optimal economic order quantity before the purchasing price increase, $Q^{*}$, i.e., $Q_{s} \geq Q^{*}$.

8) There is no replacement or repair of deteriorated units during the period of the consideration.

9) The replenishment is instantaneous and the lead time is zero.

\section{MODEL FORMULATION}

The integrated inventory system evolves as follows: the buyer orders $Q$ units per order and the vendor delivers $Q$ units to the buyer in each shipment. Following, we first establish the joint total profit per unit time before the price of material increases. And then the joint profit increase between the special order and regular order during the special cycle time is developed.

\section{A. The Buyer'S Total Profit Per Unit Time}

The depletion of the inventory occurs due to the combined effects of demand and physical deterioration. Hence, the change in inventory level before the purchasing price increase can be illustrated by the following differential equation:

$$
d I(t) / d t=-\theta_{b} I(t)-D(p), \quad 0<t<T .
$$

Given the boundary condition $I(T)=0$, the solution of $(1)$ can be represented by

$$
I(t)=D(p)\left[e^{\theta_{b}(T-t)}-1\right] / \theta_{b}, 0 \leq t \leq T
$$

Thus, the order quantity is given by

$$
Q=I(0)=D(p)\left(e^{\theta_{b} T}-1\right) / \theta_{b} .
$$

Prior to the purchasing price increase, the buyer follows the regular economic order policy with unit purchasing cost, $v$, and sell them with unit retail price, $p$. In this situation, the total profit during the replenishment period $T$ is the total revenue $\left(p \int_{0}^{T} D(p) d t\right)$ minus the total relevant costs which are including the ordering cost $(A)$, purchasing cost $(v Q)$ and holding cost $\left(h_{b} v \int_{0}^{T} I(t) d t\right)$. That is,

$$
\begin{aligned}
& p \int_{0}^{T} D(p) d t-\left[A+v Q+h_{b} v \int_{0}^{T} I(t) d t\right] \\
& \quad=(p-v) D(p) T-\frac{\left(\theta_{b}+h_{b}\right) v D(p)}{\theta_{b}{ }^{2}}\left(e^{\theta_{b} T}-\theta_{b} T-1\right)-A .
\end{aligned}
$$

Therefore, the buyer's total profit per unit time is

$$
\begin{aligned}
T P B(p, T)= & \frac{1}{T}\{(p-v) D(p) T \\
& \left.-\frac{\left(\theta_{b}+h_{b}\right) v D(p)}{\theta_{b}^{2}}\left(e^{\theta_{b} T}-\theta_{b} T-1\right)-A\right\} .
\end{aligned}
$$

\section{B. The Vender'S Total Profit per Unit Time}

The change in inventory level before the price of material increase can be illustrated by the following differential equation:

$$
d I_{v}(t) / d t=P-\theta_{v} I(t), \quad 0<t<T_{v} .
$$

Given the boundary condition $I_{v}(0)=0$, the solution of (6) can be represented by

$$
I_{v}(t)=P\left(1-e^{-\theta_{v} t}\right) / \theta_{v}, 0<t<T_{v} .
$$

Thus, the production quantity in a production cycle is

$$
Q=I_{v}\left(T_{v}\right)=P\left(1-e^{-\theta_{v} T_{v}}\right) / \theta_{v}
$$

Prior to the material price increase, the vender follows the regular economic production policy with unit production cost, $c$, and sell them with unit supply price, $v$. In this situation, the total profit during the production period $T_{v}$ is the total revenue $(v Q)$ minus the total relevant costs which are including the set-up cost $(S)$, production cost $\left(c P T_{v}\right)$ and holding cost $\left(h_{v} c \int_{0}^{T_{v}} I_{v}(t) d t\right)$. That is,

$$
\begin{aligned}
v Q- & S-c P T_{v}-h_{v} c \int_{0}^{T_{v}}(t) d t \\
& =(v-c) P T_{v}+\frac{\left(\theta_{v} v+h_{v} c\right) P}{\theta_{v}^{2}}\left(1-\theta_{v} T_{v}-e^{-\theta_{v} T_{v}}\right)-S .
\end{aligned}
$$

Therefore, the vendor's total profit per unit time is

$$
\begin{aligned}
T P V\left(T_{v}\right) & =\frac{1}{T_{v}}\left[(v-c) P T_{v}+\frac{\left(\theta_{v} v+h_{v} c\right) P}{\theta_{v}^{2}}\right. \\
& \left.\times\left(1-\theta_{v} T_{v}-e^{-\theta_{v} T_{v}}\right)-S\right] .
\end{aligned}
$$

\section{The Joint Total Profit per Unit Time}

Once the buyer and vendor have built up a long-term strategic partnership, they can jointly determine the best policy for both parties. Accordingly, the joint total profit per unit time can be obtained as the sum of the buyer's and the vendor's total profits per unit time. That is,

$$
\begin{aligned}
& J T P\left(p, T, T_{v}\right)=T P B(p, T)+T P V\left(T_{v}\right) \\
& =(p-v) D(p)-\frac{\left(\theta_{b}+h_{b}\right) v D(p)}{\theta_{b}^{2} T}\left(e^{\theta_{b} T}-\theta_{b} T-1\right)-\frac{A}{T} \\
& \quad+(v-c) P+\frac{\left(\theta_{v} v+h_{v} c\right) P}{\theta_{v}^{2} T_{v}}\left(1-\theta_{v} T_{v}-e^{-\theta_{v} T_{v}}\right)-\frac{S}{T_{v}} .
\end{aligned}
$$

From (3) and (8), we have $D(p)\left(e^{\theta_{b} T}-1\right) / \theta_{b}$ $=P\left(1-e^{-\theta_{v} T_{v}}\right) / \theta_{v}$, and hence

$$
T_{v}=\ln \left[\theta_{b} P /\left\{\theta_{b} P-\theta_{v} D(p)\left(e^{\theta_{b} T}-1\right)\right\}\right] / \theta_{v} .
$$

It notes that $\theta_{b} P>\theta_{v} D(p)\left(e^{\theta_{b} T}-1\right)$. Substituting (12) into (11), $\operatorname{JTP}\left(p, T, T_{v}\right)$ can be reduced to $\operatorname{JTP}(p, T)$ and is given by 


$$
\begin{gathered}
J T P(p, T)=\frac{\left(\theta_{b} p+h_{b} v\right) D(p)}{\theta_{b}}-\frac{\left(\theta_{b}+h_{b}\right) v D(p)}{\theta_{b}^{2} T}\left(e^{\theta_{b} T}-1\right) \\
-\frac{\left(\theta_{v}+h_{v}\right) c P}{\theta_{v}}-\frac{A}{T}+\frac{\left(\theta_{v} v+h_{v} c\right) D(p)\left(e^{\theta_{b} T}-1\right)-\theta_{b} \theta_{v} S}{\theta_{b} \ln \left[\frac{\theta_{b} P}{\theta_{b} P-\theta_{v} D(p)\left(e^{\theta_{b} T}-1\right)}\right]} .
\end{gathered}
$$

The objective of this problem is to determine the optimal pricing, ordering and production policies that correspond to maximizing the joint total profit per unit time. The optimal solutions can be obtained by using the following search procedure: We first prove that for any given retail price $p$, the optimal value of $T$ not only exists but also is unique. And then for any given value of $T$, there exists a unique sell pricing $p$ to maximize the objective function. The processes of proofs are similar to [32-34], and hence are omitted here. Once the optimal retail price, $p^{*}$, and the length of replenishment cycle time, $T^{*}$, are obtained, the length of production cycle time, $T_{v}{ }^{*}$, and the optimal order quantity, $Q^{*}$, are given as follows:

$$
T_{v}^{*}=\ln \left[\theta_{b} P /\left\{\theta_{b} P-\theta_{v} D\left(p^{*}\right)\left(e^{\theta_{b} T^{*}}-1\right)\right\}\right] / \theta_{v},
$$

and

$$
Q^{*}=D\left(p^{*}\right)\left(e^{\theta_{b} T^{*}}-1\right) / \theta_{b} .
$$

Next, when the supply price changes from $v$ to $v_{r}$ due to the production cost changes from $c$ to $c_{r}$, if the buyer does not replace a special order before the price increases, then he/she will reflect the supply price changes on the retail price. Hence, the retail price increases from $p$ to $p_{r}$. In this situation, the joint total profit per unit time becomes

$$
\begin{aligned}
& J T P_{r}\left(p_{r}, T_{r}\right)=\frac{\left(\theta_{b} p_{r}+h_{b} v_{r}\right) D\left(p_{r}\right)}{\theta_{b}}-\frac{\left(\theta_{b}+h_{b}\right) v_{r} D\left(p_{r}\right)}{\theta_{b}^{2} T_{r}}\left(e^{\theta_{b} T_{r}}-1\right) \\
& -\frac{\left(\theta_{v}+h_{v}\right) c_{r} P}{\theta_{v}}-\frac{A}{T_{r}}+\frac{\left(\theta_{v} v_{r}+h_{v} c_{r}\right) D\left(p_{r}\right)\left(e^{\theta_{b} T_{r}}-1\right)-\theta_{b} \theta_{v} S}{\theta_{b} \ln \left[\theta_{b} P /\left[\theta_{b} P-\theta_{v} D\left(p_{r}\right)\left(e^{\theta_{b} T_{r}}-1\right)\right]\right]} .
\end{aligned}
$$

By using the similar argument as above, once the optimal retail price, $p_{r}{ }^{*}$, and the length of replenishment cycle time, $T_{r}^{*}$, are obtained, the optimal length of production cycle time, $T_{r_{v}}^{*}$, and order quantity, $Q_{r}{ }^{*}$, are as follows:

$$
T_{r_{v}}^{*}=\ln \left[\theta_{b} P /\left\{\theta_{b} P-\theta_{v} D\left(p_{r}^{*}\right)\left(e^{\theta_{b} T_{r}^{*}}-1\right)\right\}\right] / \theta_{v},
$$

And

$$
Q_{r}^{*}=D\left(p_{r}^{*}\right)\left(e^{\theta_{b} T_{r}^{*}}-1\right) / \theta_{b}
$$

Subsequently, when the vendor announces a supply price increase (from $v$ to $v_{r}$ ) that is effective starting on a particular future date, the buyer may place a special order to take advantage of the relative lower supply price before the price increases. In order to response the marketing situation, the buyer will reflect supply price changes on retail price.

Our purpose is to determine the optimal special order quantity and the retail price by maximizing the joint total profit increase between special and regular orders during the depletion time of the special order quantity. Due to the vendor may or not provide all the special order quantity at the buyer's next replenishment date and hence the shortage will or not occur, two specific situations are discussed in this study: (i) $T_{c}+T_{s_{v}} \leq T^{*}$ and (ii) $T_{c}+T_{s_{v}}>T^{*}$. Next, we will formulate the corresponding joint total profit increasing function for these two cases.

Case 1: $T_{c}+T_{s_{v}} \leq T^{*}$

In this case, the vendor can provide all the special order quantity at the buyer's next replenishment date and hence the shortage will not occur. If the buyer decides to adopt a special order policy and orders $Q_{s}$ units, then the inventory level at time $t$ will be

$$
I_{s}(t)=D\left(p_{s}\right)\left[e^{\theta_{b}\left(T_{s}-t\right)}-1\right] / \theta_{b}, 0 \leq t \leq T_{s} .
$$

The special order quantity with the original unit purchasing price, $v$, is

$$
Q_{s}=I_{s}(0)=D\left(p_{s}\right)\left[e^{\theta_{b} T_{s}}-1\right] / \theta_{b} .
$$

For the buyer, the total profit of the special order during the time interval $\left[0, T_{s}\right]$ (denoted by $\operatorname{TPBS}_{1}\left(p_{s}, T_{s}\right)$ ) is equal to total revenue minus the total relevant cost which consists of the ordering cost, purchasing cost and holding cost, and can be expressed by

$$
\begin{aligned}
\operatorname{TPBS}_{1}\left(p_{s}, T_{s}\right)= & \left(p_{s}-v\right) D\left(p_{s}\right) T_{s}-\frac{\left(\theta_{b}+h_{b}\right) v D\left(p_{s}\right)}{\theta_{b}^{2}} \\
& \times\left(e^{\theta_{b} T_{s}}-\theta_{b} T_{s}-1\right)-A .
\end{aligned}
$$

As to the vendor, if the buyer decides to adopt a special order policy and orders $Q_{s}$ units, the inventory level at time $t$ will be

$$
I_{s_{v}}(t)=P\left(1-e^{-\theta_{v} t}\right) / \theta_{v}, 0<t<T_{s_{v}} .
$$

Thus, the special production quantity is given by

$$
Q_{s}=I_{s_{v}}\left(T_{s_{v}}\right)=P\left(1-e^{-\theta_{v} T_{s_{v}}}\right) / \theta_{v} .
$$

Similarly, the total profit of the special order during the time interval $\left[0, T_{s v}\right]$ (denoted by $\operatorname{TPVS}_{1}\left(T_{s v}\right)$ ) is equal to total revenue minus the total relevant cost which consists of the set-up cost, production cost and holding cost, and can be expressed by

$$
\begin{aligned}
\operatorname{TPVS}_{1}\left(T_{s_{v}}\right)= & (v-c) P T_{s_{v}}+\frac{\left(\theta_{v} v+h_{v} c\right) P}{\theta_{v}^{2}}\left(1-\theta_{v} T_{s_{v}}-e^{-\theta_{v} T_{s_{v}}}\right) \\
& -S .
\end{aligned}
$$

Consequently, the joint total profit when the buyer decides to adopt a special order policy can be obtained as the sum of the buyer's and the vendor's total profits per unit time. That is,

$$
\begin{aligned}
& J T P S_{1}\left(p_{s}, T_{s}, T_{s_{v}}\right)=\operatorname{TPBS} S_{1}\left(p_{s}, T_{s}\right)+\operatorname{TPV} S_{1}\left(T_{s_{v}}\right) \\
& =\left(p_{s}-v\right) D\left(p_{s}\right) T_{s}-\frac{\left(\theta_{b}+h_{b}\right) v D\left(p_{s}\right)}{\theta_{b}^{2}}\left(e^{\theta_{b} T_{s}}-\theta_{b} T_{s}-1\right)-A \\
& \quad+(v-c) P T_{s_{v}}+\frac{\left(\theta_{v} v+h_{v} c\right) P}{\theta_{v}^{2}}\left(1-\theta_{v} T_{s_{v}}-e^{-\theta_{v} T_{s_{v}}}\right)-S .(25)
\end{aligned}
$$

From (20) and (23), we have

$$
T_{s_{v}}=\ln \left[\theta_{b} P /\left\{\theta_{b} P-\theta_{v} D\left(p_{s}\right)\left(e^{\theta_{b} T_{s}}-1\right)\right\}\right] / \theta_{v} .
$$

It notes that $\theta_{b} P>\theta_{v} D\left(p_{s}\right)\left(e^{\theta_{b} T_{s}}-1\right)$. Hence, $J T P S_{1}\left(p_{s}, T_{s}\right.$, $\left.T_{s v}\right)$ can be reduced to $\operatorname{JTPS}_{1}\left(p_{s}, T_{s}\right)$ as 


$$
\begin{aligned}
\operatorname{JTPS}_{1}( & \left.p_{s}, T_{s}\right)=\frac{\left(\theta_{b} p_{s}+h_{b} v\right) D\left(p_{s}\right) T_{s}}{\theta_{b}}-A-S \\
& +\frac{\left(h_{v} \theta_{b} c-h_{b} \theta_{v} v\right) D\left(p_{s}\right)\left(e^{\theta_{b} T_{s}}-1\right)}{\theta_{v} \theta_{b}^{2}}-\frac{\left(\theta_{v}+h_{v}\right) c P}{\theta_{v}^{2}} \\
& \times \ln \left[\frac{\theta_{b} P}{\theta_{b} P-\theta_{v} D\left(p_{s}\right)\left(e^{\theta_{b} T_{s}}-1\right)}\right] .
\end{aligned}
$$

Due to $T_{c}+T_{s_{v}} \leq T^{*}$, substituting $T_{s_{v}}$ in (26) into the inequality $T_{c}+T_{s_{v}} \leq T^{*}$, we have

$$
T_{s} \leq \frac{1}{\theta_{b}} \ln \left[\frac{\theta_{b} P\left[1-e^{-\theta_{v}\left(T^{*}-T_{c}\right)}\right]+\theta_{v} D\left(p_{s}\right)}{\theta_{v} D\left(p_{s}\right)}\right] \equiv T_{U} .
$$

If the vendor and buyer adopt its regular EPQ and EOQ policies, then the joint total profit during the time interval $\left[0, T_{s}\right]$ will be divided into two periods (see Figure 1). In the first period, the buyer orders $Q^{*}$ units at the unit purchasing price $v$ and retail price $p$. The corresponding joint total profit is similar (11), and is $\operatorname{TPB}\left(p^{*}, T^{*}\right) T^{*}+T P V\left(T_{v}^{*}\right) T_{v}^{*}$.
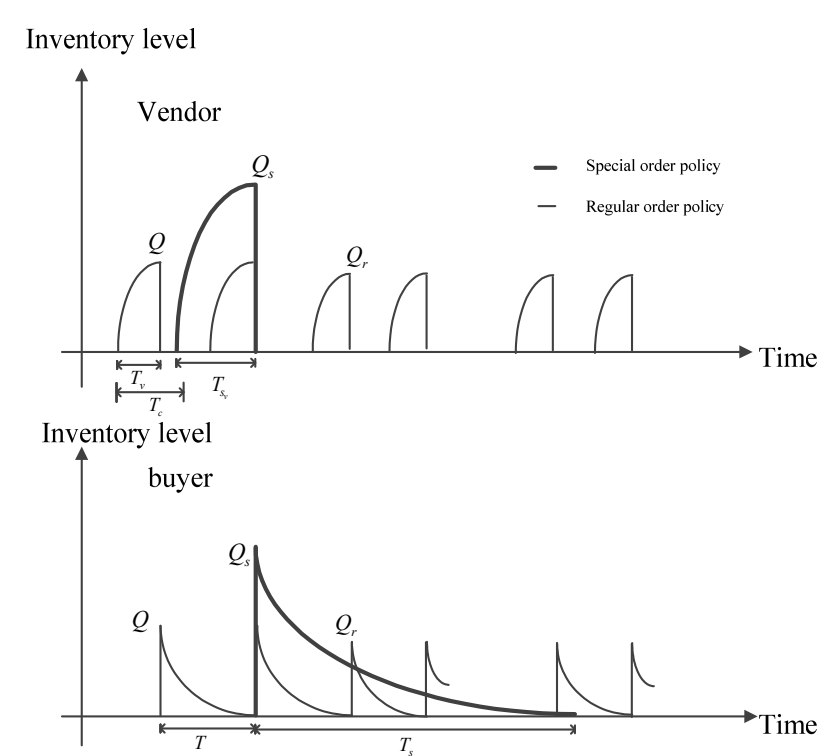

Fig. 1. Special vs. regular order policies when $T_{c}+T_{s_{v}} \leq T^{*}$.

As to the rest period, the vendor and buyer follows regular EPQ and EOQ policies with the unit production cost $c_{r}$, purchasing price $v_{r}$ and retail price $p_{r}$. Thus, the joint total profit during the rest period is

$$
\frac{T_{s}+T_{s_{v}}-\left(T^{*}+T_{v}^{*}\right)}{T_{r}^{*}+T_{v_{r}}^{*}}\left[T P B_{r}\left(p_{r}^{*}, T_{r}^{*}\right) T_{r}^{*}+T P V_{r}\left(T_{v_{r}}^{*}\right) T_{v_{r}}^{*}\right],
$$

where $T_{s_{v}}$ is shown as in (26)

Consequently, the joint total profit of a regular EPQ and EOQ policies during the time interval $\left[0, T_{s}\right]$ (denoted by $\left.J T P N_{1}\left(p_{s}, T_{s}\right)\right)$ is

$$
\begin{aligned}
\operatorname{JTPN}_{1}\left(p_{s}, T_{s}\right)= & \operatorname{PPB}\left(p^{*}, T^{*}\right) T^{*}+\operatorname{TPV}\left(T_{v}^{*}\right) T_{v}^{*}+\frac{T_{s}+T_{s_{v}}-\left(T^{*}+T_{v}^{*}\right)}{T_{r}^{*}+T_{v_{r}}^{*}} \\
& \times\left[T P B_{r}\left(p_{r}^{*}, T_{r}^{*}\right) T_{r}^{*}+T P V_{r}\left(T_{v_{r}}^{*}\right) T_{v_{r}}^{*}\right]
\end{aligned}
$$

Comparing (27) with (30), the joint total profit increase for Case 1 can be given by

$$
g_{1}\left(p_{s}, T_{s}\right)=J T P S_{1}\left(p_{s}, T_{s}\right)-J T P N_{1}\left(p_{s}, T_{s}\right),
$$

where $J T P S_{1}\left(p_{s}, T_{s}\right)$ and $J T P N_{1}\left(p_{s}, T_{s}\right)$ are shown as in (27) and (30).

Due to the high-power expression of the exponential function, we could not obtain a sound result. Instead, we first prove that for any given the buyer's selling price $p_{s}$, the optimal value of $T_{s}$ not only exists but also is unique. And then for any given value of $T_{s}$, there exists a unique sell pricing $p_{s}$ to maximize the joint total profit increase. Due to limited contexts available, we omit the solution procedure and the algorithm here.

Case 2. $T_{c}+T_{s_{v}}>T^{*}$

In this case, the vendor is unable to provide all the special order quantity at the buyer's next replenishment date and hence the shortage will occur. If the buyer decides to adopt a special order policy and orders $Q_{\mathrm{s}}$ units, then the inventory level at time $t$ will be

$$
I_{s}(t)=\left\{\begin{array}{cr}
-D\left(p^{*}\right) t, & 0 \leq t \leq t_{s}, \\
\left.D\left(p_{s}\right)\left[e^{\theta_{b}\left(T_{s}-t\right)}-1\right] / \theta_{b}^{2}, 8\right) & t_{s} \leq t \leq T_{s} .
\end{array}\right.
$$

The special order quantity with the original unit purchasing price, $v$, is

$$
Q_{s}=D\left(p_{s}\right)\left[e^{\theta_{b}\left(T_{s}-t_{s}\right)}-1\right] / \theta_{b}+D\left(p^{*}\right) t_{s} .
$$

For the buyer, the total profit of the special order during the time interval $\left[t_{s}, T_{s}\right]$ (denoted by $\left.\operatorname{TPB} S_{2}\left(p_{s}, t_{s}, T_{s}\right)\right)$ is equal to total revenue $p_{s} D\left(p_{s}\right)\left(T_{s}-t_{s}\right)+p^{*} D\left(p^{*}\right) t_{s}$, minus the total relevant costs which consist of the ordering cost $A$, purchasing cost $v Q_{s}$, holding cost $h_{b} v \int_{t_{s}}^{T_{s}} I_{s}(t) d t$, and shortage cost $\pi \int_{0}^{t_{s}}-I_{s}(t) d t$, and can be expressed by

$$
\begin{gathered}
T P B S_{2}\left(p_{s}, t_{s}, T_{s}\right)=\frac{\left(\theta_{b} p_{s}+h_{b} v\right) D\left(p_{s}\right)\left(T_{s}-t_{s}\right)}{\theta_{b}}+\left(p^{*}-v\right) D\left(p^{*}\right) t_{s} \\
-\frac{\left(h_{b}+\theta_{b}\right) v D\left(p_{s}\right)\left[e^{\theta_{b}\left(T_{s}-t_{s}\right)}-1\right]}{\theta_{b}^{2}}-\frac{\pi D\left(p^{*}\right) t_{s}^{2}}{2}-A \text {. (34) }
\end{gathered}
$$

As to the vendor, the total profit of the special production during the time interval $\left[0, T_{s v}\right]$ (denoted by $T P V S_{2}\left(T_{s v}\right)$ ) is the same as Case 1, and can be expressed by

$$
\operatorname{TPVS}_{2}\left(T_{s_{v}}\right)=\operatorname{TPVS} S_{1}\left(T_{s_{v}}\right) .
$$

Consequently, the joint total profit when the buyer adopts a special order policies can be obtained as the sum of the buyer's and the vendor's total profits per unit time. That is,

$$
\begin{aligned}
& \operatorname{JTPS}_{2}\left(p_{s}, t_{s}, T_{s}, T_{s_{v}}\right)=\frac{\left(\theta_{b} p_{s}+h_{b} v\right) D\left(p_{s}\right)\left(T_{s}-t_{s}\right)}{\theta_{b}}-A-S \\
& +\left(p^{*}-v\right) D\left(p^{*}\right) t_{s}-\frac{\left(h_{b}+\theta_{b}\right) v D\left(p_{s}\right)\left[e^{\theta_{b}\left(T_{s}-t_{s}\right)}-1\right]}{\theta_{b}^{2}}-\frac{\pi D\left(p^{*}\right) t_{s}^{2}}{2} \\
& +(v-c) P T_{s_{v}}+\frac{\left(\theta_{v} v+h_{v} c\right) P}{\theta_{v}^{2}}\left(1-\theta_{v} T_{s_{v}}-e^{-\theta_{v} T_{s_{v}}}\right)
\end{aligned}
$$

From (23) and (33), we have

$$
T_{s_{v}}=\frac{1}{\theta_{v}} \ln \left[\frac{\theta_{b} P}{\theta_{b} P-\theta_{v}\left\{D\left(p_{s}\right)\left[e^{\theta_{b}\left(T_{s}-t_{s}\right)}-1\right]+\theta_{b} D\left(p^{*}\right) t_{s}\right\}}\right] .
$$


That is, $J T P S_{2}\left(p_{s}, t_{s}, T_{s}, T_{s v}\right)$ can be reduced to $J T P S_{2}\left(p_{s}, t_{s}, T_{s}\right)$ and is given by

$$
\begin{aligned}
J T P S_{2} & \left(p_{s}, t_{s}, T_{s}\right)=\frac{\left(\theta_{b} p_{s}+h_{b} v\right) D\left(p_{s}\right)\left(T_{s}-t_{s}\right)}{\theta_{b}}-(A+S) \\
& +\left(p_{s}-v\right) D\left(p^{*}\right) t_{s}+\frac{\left(h_{v} \theta_{b} c-h_{b} \theta_{v} v\right) D\left(p_{s}\right)\left[e^{\theta_{b}\left(T_{s}-t_{s}\right)}-1\right]}{\theta_{v} \theta_{b}^{2}} \\
& +\frac{\left(\theta_{b} p^{*}+h_{v} c\right) D\left(p^{*}\right) t_{s}}{\theta_{v}}-\frac{\pi D\left(p^{*}\right) t_{s}^{2}}{2}-\frac{\left(h_{v}+\theta_{v}\right) c P}{\theta_{v}} \\
& \times \ln \left[\frac{\theta_{b} P}{\theta_{b} P-\theta_{v}\left\{D\left(p_{s}\right)\left[e^{\theta_{b}\left(T_{s}-t_{s}\right)}-1\right]+\theta_{b} D\left(p^{*}\right) t_{s}\right\}}\right]
\end{aligned}
$$

If the buyer adopts its regular order policy, then the joint total profit of a regular order during the time interval $\left[0, T_{s}\right]$ will be divided into two periods (see Figure 2). In the first period, the buyer orders $Q^{*}$ units at the unit purchasing price $v$ and retail price $p$. The corresponding joint total profit is similar to (11), and is $\operatorname{TPB}\left(p^{*}, T^{*}\right) T^{*}+\operatorname{TPV}\left(T_{v}^{*}\right) T_{v}^{*}$.

As to the rest period, the vendor and buyer follows regular EPQ and EOQ policies with the unit production cost $c_{r}$, purchasing price $v_{r}$ and retail price $p_{r}$. Thus, the joint total profit during the rest period is

$$
\frac{T_{s}+T_{s_{v}}-\left(T^{*}+T_{v}^{*}\right)}{T_{r}^{*}+T_{v_{r}}^{*}}\left[T P B_{r}\left(p_{r}^{*}, T_{r}^{*}\right) T_{r}^{*}+T P V_{r}\left(T_{v_{r}}^{*}\right) T_{v_{r}}^{*}\right]
$$

Consequently, the joint total profit of a regular EPQ and EOQ policies during the time interval $\left[0, T_{s}\right]$ (denoted by $J T P N_{2}(p$, $\left.\left.t_{s}, T_{s}\right)\right)$ is

$$
\begin{aligned}
& J T P N_{2}\left(p_{s}, t_{s}, T_{s}\right)=\operatorname{TPB}\left(p^{*}, T^{*}\right) T^{*}+\operatorname{TPV}\left(T_{v}^{*}\right) T_{v}^{*} \\
& +\frac{T_{s}+T_{s_{v}}-\left(T^{*}+T_{v}^{*}\right)}{T_{r}^{*}+T_{v_{r}}^{*}}\left[T P B_{r}\left(p_{r}^{*}, T_{r}^{*}\right) T_{r}^{*}+T P V_{r}\left(T_{v_{r}}^{*}\right) T_{v_{r}}^{*}\right]
\end{aligned}
$$

Comparing (37) with (39), the joint total profit increase for Case 2 can be given by

$$
g_{2}\left(p_{s}, t_{s}, T_{s}\right)=J T P S_{2}\left(p_{s}, t_{s}, T_{s}\right)-J T P N_{2}\left(p_{s}, t_{s}, T_{s}\right), \text { (40) }
$$

where $J T P S_{2}\left(p_{s}, t_{s}, T_{s}\right)$ and $J T P N_{2}\left(p_{s}, t_{s}, T_{s}\right)$ are shown as in (37) and (39).
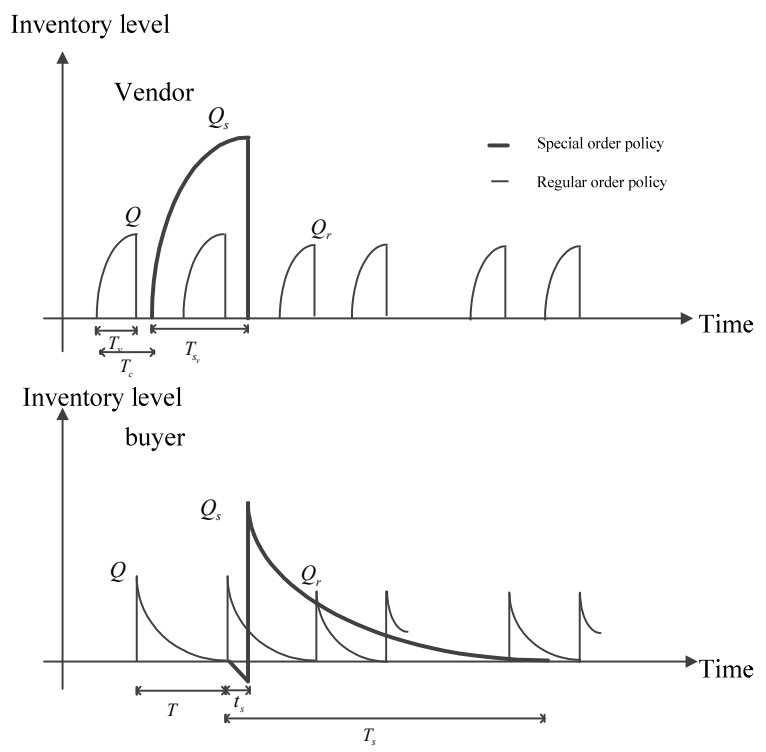

Fig. 2. Special vs. regular order policies when $T_{c}+T_{s_{v}}>T^{*}$.
Similarly, due to the high-power expression of the exponential function, we could not obtain a sound result. Instead, we first prove that for any given the buyer's selling price $p_{s}$, the optimal value of $\left(t_{s}, T_{s}\right)$ not only exists but also is unique. And then for any given value of $\left(t_{s}, T_{s}\right)$, there exists a unique sell pricing $p_{s}$ to maximize the joint total profit increase. Due to limited contexts available, we omit the solution procedure and the algorithm here.

Finally, we develop a simple algorithm to illustrate the step-by-step solution procedure for finding the optimal solution as follows.

\section{Algorithm}

Step 1. Determine $T^{*}, Q^{*}, p^{*}, T_{r}^{*}$, and $p_{r}^{*}$, respectively. Step 2. Calculate optimal value of $\left(p_{s}, T_{s}, T_{s v}\right)$ for Case 1. Step 3. Calculate optimal value of $\left(p_{s}, t_{s}, T_{s}, T_{s v}\right)$ for Case 2. Step 4. Compare $T_{s_{v}}$ which is shown as in (26) with $T^{*}-T_{c}$. If $T_{s v} \leq T^{*}-T_{c}$, then substitute optimal value of $\left(p_{s}, T_{s}\right.$, $T_{s v}$ ) into (31) to evaluate $g_{1}^{*}$; otherwise, set $g_{1}^{*}=-\infty$.

Step 5. Compare $T_{s_{v}}$ which is shown as in (36) with $T^{*}-T_{c}$. If $T_{s v}>T^{*}-T_{c}$, then substitute optimal value of $\left(p_{s}, t_{s}, T_{s}\right.$, $T_{s v}$ ) into (40) to evaluate $g_{2}^{*}$; otherwise, set $g_{2}^{*}=-\infty$.

Step 6. Find $\underset{i=1,2}{\operatorname{Max}} g_{i}$.

\section{NUMERICAL EXAMPLES}

To illustrate the optimal ordering policy, the following examples are presented:

Example 1. Given an inventory system with the following parameters:

$D(p)=1000-8 p$, where $p<125, P=1500, v=30, c=10, v_{r}=35$, $c_{r}=12, A=250, S=300, \theta_{b}=0.06, \theta_{v}=0.05, h_{b}=0.3, h_{v}=0.2$ and $T_{c}=0.2$ in appropriate units. It is shown that the increase rates of unit production and supply price are $\left[\left(c_{r}-c\right) / c\right]$ $\times 100 \%=20 \%$ and $\left[\left(v_{r}-v\right) / v\right] \times 100 \%=16.67 \%$, respectively. From the algorithm, we can obtain the optimal retail price, length of replenishment cycle time and order quantity as shown in Table I.

TABLE I: The OPtimAL SOLUTIONS BEFORE AND AFTER PRICE INCREASE IN

\begin{tabular}{|c|c|c|c|}
\hline & $\begin{array}{c}\text { optimal } \\
\text { retail price }\end{array}$ & $\begin{array}{c}\text { optimal length of } \\
\text { replenishment cycle } \\
\text { time }\end{array}$ & $\begin{array}{c}\text { optimal } \\
\text { order } \\
\text { quantity }\end{array}$ \\
\hline $\begin{array}{c}\text { Before price } \\
\text { increase }\end{array}$ & 77.9650 & 0.72099 & 277.2472 \\
\hline $\begin{array}{c}\text { After price } \\
\text { increase- regular } \\
\text { order policy }\end{array}$ & 80.5059 & 0.70124 & 254.9339 \\
\hline $\begin{array}{c}\text { After price } \\
\text { increase- special } \\
\text { order policy }\end{array}$ & 76.0497 & 2.11075 & 809.876 \\
\hline
\end{tabular}

From Table I, the buyer will reflect supply price increases on retail price with the rate $\left[\left(p_{r}{ }^{*}-p^{*}\right) / p^{*}\right] \times 100 \%=3.26 \%$ which is less than the increase rates of unit production and supply price. Furthermore, when the vendor announces a price increase that is effective starting on a particular future date, the optimal value of $g^{*}=g_{2}{ }^{*}=2278.51$ and the change rate on retail price is $\left[\left(p_{s}{ }^{*}-p^{*}\right) / p^{*}\right] \times 100 \%=-2.46 \%$. From 
the economical viewpoint, the buyer will place a special order to take advantage of current lower purchasing cost before supply price increases. And then he/she will reflect the cost saving on retail price which is related to market demand to increase the joint total profit.

Example 2. The data used is the same as those in Example 1 except we consider the case with quadratic demand function, $D(p)=1000+8 p-0.5 p^{2}$, where $8<p<53.4312$. Similarly, we can obtain the optimal retail price, length of replenishment cycle time and order quantity as shown in Table 2.

TABLE II. THE OptimAL SOLUTIONS Before AND AfTER Price INCREASE IN EXAMPLE 2.

\begin{tabular}{|c|c|c|c|}
\hline & $\begin{array}{c}\text { optimal } \\
\text { retail price }\end{array}$ & $\begin{array}{c}\text { optimal length of } \\
\text { replenishment cycle } \\
\text { time }\end{array}$ & $\begin{array}{c}\text { optimal order } \\
\text { quantity }\end{array}$ \\
\hline $\begin{array}{c}\text { Before price } \\
\text { increase }\end{array}$ & 42.9581 & 0.6521 & 279.9334 \\
\hline $\begin{array}{c}\text { After price } \\
\text { increase- regular } \\
\text { order policy }\end{array}$ & 45.1820 & 0.7295 & 254.0873 \\
\hline $\begin{array}{c}\text { After price } \\
\text { increase- special } \\
\text { order policy }\end{array}$ & 39.0689 & 2.5133 & 1176.7884 \\
\hline
\end{tabular}

From Table II, the buyer will reflect supply price increases on retail price with the rate $\left[\left(p_{r}{ }^{*}-p^{*}\right) / p^{*}\right] \times 100 \%=5.18 \%$ which is less than the increase rates of unit production and supply price. When the vendor announces a price increase that is effective starting on a particular future date, the optimal value of $g^{*}=g_{2}{ }^{*}=4335.15$ and the change rate on retail price is $\left[\left(p_{s}{ }^{*}-p^{*}\right) / p^{*}\right] \times 100 \%=-9.05 \%$. The insights are similar to Example 1.

\section{CONCLUSIONS AND Future RESEARCH}

In this paper, we investigate the supply chain inventory problem when the price increases where demand rate depends on retail price. From the point of view of the vendor, he/she will determine the optimal production policy with the increase in the price of raw material. And then he/she will reflect the increasing cost on supply price (the buyer's purchase cost) and allow the buyer to make a special order. From the buyer's viewpoint, the buyer will adopt a special order policy to determine the optimal special order quantity and retail price when demand rate depends on retail price. A simple algorithm to find the optimal solution is provided. Two numerical examples are presented to demonstrate the developed models and solution procedures. From the numerical results, we have that the buyer will place a special order to take advantage of current lower purchasing cost before supply price increases. And then he/she reflects the cost saving on retail price which is related to market demand to increase the joint profit.

The proposed model can be extended in several ways. For example, it is usually observed in the supermarket that display of the consumer goods in large quantities attracts more customers and generates higher demand. Hence, the proposed inventory model may deal with the demand rate as a function of the on-hand inventory. Furthermore, time value of money is not considered in this study. In the future, we hope the model can also be generalized to take time value of money into account.

\section{ACKNOWLEDGMENT}

The authors greatly appreciate the anonymous referees for their valuable and helpful suggestions regarding earlier version of the paper.

\section{REFERENCES}

[1] E. Naddor, Inventory Systems. Wiley, New York, 96-102, 1966.

[2] B. Lev and A. L. Soyster, "An inventory model with finite horizon and price changes," Journal of the Operational Research Society, vol. 30, pp. 43-53, 1979.

[3] S. K. Goyal, "A note on the paper: An inventory model with finite horizon and price changes," Journal of the Operational Research Society, vol. 30, pp. 839-842, 1979

[4] S. G. Taylor and C. E. Bradley, "Optimal ordering strategies for announced price increases," Operations Research, vol. 33, pp. 312-325, 1985.

[5] B. Lev and H. J. Weiss, "Inventory models with cost changes," Operations Research, vol. 38, pp. 53-63, 1990.

[6] S. K. Goyal, G. Srinivasan and F.J. Arcelus, "One time only incentives and inventory policies," European Journal of Operational Research, vol. 54, pp. 1-6, 1991

[7] R. J. Tersine, "Economic replenishment strategies for announced price increases," European Journal of Operational Research, vol. 92, pp. 266-280, 1996.

[8] A. K. Ghosh, "On some inventory models involving shortages under an announced price increase," International Journal of Systems Science, vol. 34, pp. 129-137, 2003.

[9] W. Huang and V. G. Kulkarni, "Optimal EOQ for announced price increases in infinite horizon," Operations Research, vol. 51, pp. 336-339, 2003.

[10] S. Sharma, "On price increases and temporary price reductions with partial backordering," European Journal of Industrial Engineering, 3, 70-89, 2009

[11] S. L. David, K. Philip and S. L. Edith, Designing and managing the supply chain: concepts, strategies, and case studies. $2^{\text {nd }}$ ed. The McGraw-Hill, 2003.

[12] S. K. Goyal, "An integrated inventory model for a single supplier-single customer problem," International Journal of Production Research, vol. 15, pp. 107-111, 1976.

[13] A. Banerjee, "A joint economic-lot-size model for purchaser and vendor," Decision Sciences, vol. 17, pp. 292-311, 1986.

[14] S. K. Goyal, "A joint economic-lot-size model for purchaser and vendor: a comment," Decision Sciences, vol. 19, pp. 236-241, 1988

[15] L. Lu, "A one-vendor multi-buyer integrated inventory model," European Journal of Operational Research, vol. 81, pp. 312-323, 1995.

[16] J. Hahm and C. A. Yano, "The economic lot and delivery scheduling problem: The single item case," International Journal of Production Economics, vol. 28, pp. 235-252, 1992.

[17] R. Aderohunmu, A. Mobolurin, and N. Bryson, "Joint vendor-buyer policy in JIT manufacturing," Journal of the Operational Research Society, vol. 46, pp. 375-385, 1995.

[18] S. K. Goyal, “A one-vendor multi-buyer integrated inventory model: A comment," European Journal of Operational Research, vol. 82, pp. 209-210, 1995.

[19] L. R. Khan and R. A. Sarker "An optimal batch size for a JIT manufacturing system," Computers and Industrial Engineering, vol. 42, pp. 127-136, 2002.

[20] K. S. Wu and L. Y. Ouyang, "An integrated single-vendor single-buyer inventory system with shortage derived algebraically," Production Planning and Control, vol. 14, pp. 555-561, 2003.

[21] R. M. Hill and M. Omar, "Another look at the single-vendor singlebuyer integrated production-inventory problem," International Journal of Production Research, vol. 44, pp. 791-800, 2006.

[22] Y. J. Lin, "An integrated vendor-buyer inventory model with backorder price discount and effective investment to reduce ordering cost," Computers and Industrial Engineering, vol. 56, pp. 1597-1606, 2009.

[23] P. M. Ghare and G. H. Schrader, "A model for exponentially decaying inventory system," Journal of Industrial Engineering, vol. 163, pp. 238-243, 1963.

[24] R. P. Covert and G. C. Philip, "An EOQ model for items with Weibull distribution deterioration," AIIE transactions, vol. 5, no. 323-326, 1973.

[25] G. C. Philip, "A generalized EOQ model for items with Weibull distribution," AIIE Transactions, vol. 6, pp. 159-162, 1974. 
[26] Y. K. Shah, "An order-level lot size inventory model for deteriorating items," AIIE Transactions, vol. 9, pp. 108-112, 1977.

[27] S. K. Goyal and B.C. Giri, "Recent trends in modeling of deteriorating inventory," European Journal of Operational Research, vol. 134, pp. $1-6,2001$.

[28] M. Bakker, J. Riezebos and R. H. Teunter, "Review of inventory systems with deterioration since 2001," European Journal of Operational Research, vol. 221, pp. 275-284, 2012.

[29] I. Moon, B. C. Giri and B. Ko, "Economic order quantity models for ameliorating/deteriorating items under inflation and time discounting," European Journal of Operational Research, vol. 162, pp. 773-785, 2005.

[30] P. S. Deng, R. H. Lin and P. A. Chu, "A note on the inventory models for deteriorating items with ramp type demand rate," European Journal of Operational Research, vol. 178, pp. 112-120, 2007.

[31] P. Mishra and N. H. Shah, "Inventory management of time dependent deteriorating items with salvage value," Applied Mathematical Sciences, vol. 2, pp. 793-798, 2008.

[32] C. Y. Dye, "Joint pricing and ordering policy for deteriorating inventory with partial backlogging," Omega, vol. 35, pp. 184-189, 2007.

[33] K. S. Wu, L. Y. Ouyang and C. T. Yang, "Coordinating replenishment and pricing policies for non-instantaneous deteriorating items with price sensitive demand," International Journal of Systems Science, vol. 40, pp. 1273-1281, 2009.

[34] C. T. Yang, L. Y. Ouyang, and H. H. Wu, "Retailer's optimal pricing and ordering policies for non-instantaneous deteriorating items with price-dependent demand and partial backlogging" Mathematical Problems in Engineering, vol. 2009, pp. 18, 2009.

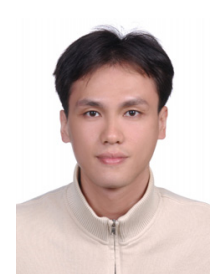

Chih-Te Yang is an Associate Professor in the Department of Industrial Management at Chien Hsin University of Science and Technology in Taiwan. He earned his Ph.D. from the Graduate Institute of Management Sciences at Tamkang University in Taiwan. His research interests are in the field of production/inventory control, and supply chain management. He has published articles in International Journal of Production Economics, European Journal of Operational Research, Computers \& Industrial Engineering, International Journal of Information and Management Sciences, Asia-Pacific Journal of Operational Research, International Journal of Systems Science, Mathematical Problems in Engineering, TOP, Journal of Scientific \& Industrial Research, Central European Journal of Operations Research and European Journal of Industrial Engineering.

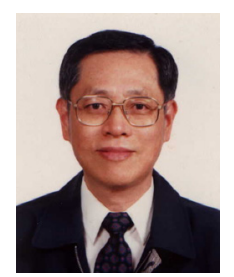

Liang-Yuh Ouyang is a Professor in the Department of Management Sciences at Tamkang University in Taiwan. He earned his M.S. in Mathematics and Ph.D. in Management Sciences from Tamkang University. His research interests are in the field of Production/Inventory Control, Probability and Statistics. He has published in Journal of the Operational Research Society, Computers \& Operations Research, European Journal of Operational Research, Computers and Industrial Engineering, International Journal of Production Economics, IEEE Transactions on Reliability, Production Planning \& Control, Mathematical and Computer Modelling, Applied Mathematical Modelling, Applied Mathematical and Computation, Journal of Global Optimization and International Journal of Systems Science. 